\title{
CRÓNICA
}

\section{Reunión del Grupo Fomento Social}

(Madrid, 27-28 noviembre 2010)

\section{Ildefonso Camacho Laraña S. I.}

Como en años anteriores, el encuentro anual del Grupo Fomento Social se celebró, en Madrid, en la Casa de Espiritualidad de las Esclavas del Sagrado Corazón (c) General Martínez Campos), desde el sábado 27 de noviembre por la mañana hasta el domingo 28 a mediodía. Los asistentes pasaron de la veintena, jesuitas en su mayoría y algunos laicos afines a la espiritualidad ignaciana y/o colaboradores en instituciones de la Compañía de Jesús. También estuvo presente en todas las sesiones el nuevo Provincial de la Compañía de Jesús en España (P. Francisco José Ruiz Pérez), que había tomado posesión de su cargo en septiembre pasado.

El tema que había sido seleccionado en el encuentro del año pasado, cuando ya comenzaban a notarse los efectos de la crisis desencadenada en 2008 sobre el proyecto europeo, fue este: "Europa: proyecto, incertidumbre, horizontes".

\section{El tema de fondo: “Europa necesita liderazgos para seguir construyendo una casa común"}

Este fue el título que se escogió para la ponencia que sería centro del encuentro. Y se encargó a D. RAMÓN JÁUREGUI ATONDO, en la actualidad Ministro de la Presidencia del Gobierno de España. El encargo le había sido hecho cuando era Diputado en el Parlamento Europeo, cargo que desempeñó en la presente legislatura europea (desde la celebración de las elecciones, el 7 de junio de 2009, hasta su nombramiento como ministro, el pasado 24 de octubre). Precisamente esta experiencia en Estrasburgo y Bruselas era la que motivó la invitación para actuar como ponente. 
Comenzó recorriendo los grandes hitos de la construcción europea, que presentó como la historia de un éxito, pero también de una exigencia continua de avance. Esta dinámica ha caracterizado un proceso, cuyo impulso fue desde el principio la aspiración a construir un espacio de paz en Europa. Por eso la dignidad y los derechos humanos han sido y son algo sustancial en el proyecto europeo. Se fijó en tres momentos decisivos: el Tratado de Maastricht (que estableció la ciudadanía europea), la ampliación de 15 a 27 miembros y, finalmente, el establecimiento de la moneda única (adoptada por 16 países en la actualidad).

El último paso importante fue el Tratado de Lisboa, la difícil salida que se encontró tras el fracasado intento de dotar a la Unión Europea de un tratado constitucional. El citado Tratado de Lisboa, que fue puesto en marcha bajo la presidencia alemana en 2007 y no pudo entrar en vigor hasta el 1 de diciembre de 2009, consiguió uno de esos difíciles equilibrios que caracterizan la construcción europea: el tener forma de tratado y alma de constitución.

Después de este recorrido histórico se detuvo en analizar los cinco problemas principales con que se enfrenta hoy la Unión Europea:

$\left.1^{\circ}\right)$ La arquitectura institucional, que no corresponde a un Estado federal y obliga a someterse a innumerables filtros y condicionantes. Siempre hay que contar con algunos líderes para que tiren del proceso (como ocurre ahora con Merkel - Sarkozy). Los 27 miembros de la Comisión no son verdaderos "ministros europeos": les falta esta dimensión de modo que cada uno piensa más en su país de origen; además, al ser de distintos partidos y orientaciones políticas, hacen más difícil articular un programa coherente.

$\left.2^{\circ}\right)$ Aparición del espíritu soberanista "renacionalizador". Tiene muchas manifestaciones. Se va perdiendo la "emoción" europeísta (se nota en España en comparación con el ambiente de los años 1980, y se puede comprobar en los datos del Eurobarómetro). Se observa una cierta fatiga de las políticas de cohesión solidaria: se dice, por ejemplo, que "Francia manda y Alemania paga"; y es cierto que Alemania hace reformas que otros países no hacen (hace cinco años se elevó en el país germano la edad de jubilación hasta los 67 años). Además se nota la ausencia de líderes en los grandes países. Por fin, son muchas las resistencias nacionales a la "invasión legislativa europea": se manifiesta siempre que, en base al principio de subsidiariedad, hay que hacer la consulta prescrita a todos los parlamentos de los países miembros (incluidos los de los Länder alemanes o las Comunidades Autónomas españolas) antes de adoptar una iniciativa legislativa, lo que da ocasión para reacciones muy defensivas en los diferentes órganos legislativos nacionales. 
$\left.3^{\circ}\right)$ Inexistencia de una política exterior común. Es un tema muy conocido. Resulta de una historia de intereses cruzados, que se deja ver siempre que hay una situación conflictiva ante la que tomar posición. ¿̇legará a haber algún día un único embajador de la Unión Europea en los países externos a ella, en lugar de 27 embajadores diferentes?

$\left.4^{\circ}\right)$ Problemas derivados de la crisis económica. Han puesto de relieve que la estructura creada por los 16 países de la zona euro es demasiado débil: no hay un tesoro común, no hay emisión de moneda, no hay presupuesto común, sino presupuestos de los Estados miembros sin posibilidad de que sean controlados por la Unión Europea. No es extraño que en esta tesitura tan delicada en que nos encontramos cunda la alarma: porque para muchos la caída del euro significaría mucho más que un fracaso parcial, significaría la caída de Europa.

$\left.5^{\circ}\right)$ Como telón de fondo está el pecado original de Europa: el eurocentrismo. A él seguimos aferrados, sin aceptar que el centro del mundo se va desplazando, sin valorar que hoy todos crecen más rápido que Europa. Por eso el reciente informe de los sabios europeos insiste en que no basta con salir de la crisis, ya que el problema es de mucho más alcance.

El ponente, ante esta visión que él mismo calificaba de preocupante, terminó indicando que el móvil del proyecto europeo ya ha dejado de ser el construir un espacio de paz, porque esto ya no atrae a las generaciones que nacieron ya en el marco de una Unión Europea en construcción. ¿̇Queda como único móvil para hacer frente a la situación el riesgo del abismo? En todo caso el modelo hacia el que queremos avanzar está sometido a debate. Y es un debate sobre el modelo del Estado de bienestar que ha inspirado la construcción europea. El ponente concluyó sugiriendo que temas como la fiscalidad y la armonización fiscal, la reforma de la gestión de los servicios públicos, la flexibilización de las plantillas, la incorporación del sistema de copago o la revisión de la edad de jubilación debían ser abordados con audacia y creatividad.

Siguió un breve diálogo en que se formularon al ponente cuestiones en torno a la inmigración selectiva en la Unión Europea, al papel de la sociedad civil, a la necesidad de una regeneración de las instituciones, a las condiciones del crecimiento económico, a la tarea que se espera desempeñe la Iglesia.

La primera parte de la tarde del sábado fue ocupada por una intervención complementaria del jesuita José IGNACIO GARCÍA JIMÉNEZ, que trabaja actualmente en 
Bruselas, en OCIPE (Oficina Católica de Información y de Iniciativa para Europa), institución fundada en Estrasburgo en 1956 para el seguimiento de los temas de la entonces recién nacida Comunidad Económica Europea. Su intervención versó sobre "La reflexión y la acción sociales de la Compañía de Jesús europea. Presentó el documento The European Context of Jesuit Mission, preparado por dicho organismo para que sirva de base a la reflexión y toma de decisiones de los Provinciales jesuitas europeos' ${ }^{1}$. En él se analizan cuatro contextos diversos (el socioeconómico y medioambiental, el político, el cultural, el religioso y eclesial) sugiriendo en cada uno los retos y las oportunidades que se ofrecerían para la actuación de la Compañía de Jesús.

\section{Comunicaciones}

El resto de la tarde del sábado y parte de la mañana del domingo se ocuparon con diversas comunicaciones e informes de miembros del Grupo.

Una primera comunicación sobre "Empadronamiento y políticas migratorias" corrió a cargo de CRISTINA MANZANEDO, de la Fundación Entreculturas. Presentó un trabajo, en el que han colaborado el Servicio Jesuita a Migrantes y Cáritas, sobre las restricciones de algunos ayuntamientos al empleo de inmigrantes en situación irregular. Este estudio tiene marcado interés en el momento actual porque en diciembre de 2010 se cumple el plazo para trasponer la Directiva de Retorno de la Unión Europea al Derecho de los Estados miembros. El estudio muestra que no hay contradicción entre la citada directiva y la legislación española sobre empadronamiento, pero constata también cómo se están difundiendo otras prácticas restrictivas para impedir que la población extranjera acceda al padrón.

El Director del Cristianisme i Justícia de Barcelona, el jesuita LIORENÇ PUIG, presentó la "Mesa de reflexión para la incidencia social de la Compañía de Jesús en España". Se trata de un grupo de personas vinculadas a la Compañía de Jesús que pretenden coordinar cosas que ya se hacen buscando el equilibrio entre generar acción transformadora y generar pensamiento.

El Presidente de la Fundación Seminario de Investigación para la Paz de Zaragoza, el jesuita Jesús María Alemany, dio cuenta de los trabajos que se están llevando

' El documento está accesible, tanto en su versión inglesa como en la castellana, en la página web de OCIPE: http://www.ocipe.info/wp-content/uploads/2010/10/EuropeanContext.pdf. 
a cabo para promover una declaración universal del derecho humano a la paz. Esta es una iniciativa de la sociedad civil, conducida por la Asociación Española para el Derecho Internacional de los Derechos Humanos, con sede en Asturias, en la que han participado más de 800 ONG de todo el mundo. La conclusión del proceso tendría lugar en un Congreso Internacional que se celebraría en Santiago de Compostela los días 9 y 10 de diciembre de 2010. El objetivo principal de dicho Congreso era aprobar la citada declaración como contribución final de la sociedad civil internacional al proceso de codificación internacional de citado derecho a la paz. La ONU dispondría así de un texto rigurosamente elaborado, a partir del cual y siguiendo los procedimientos establecidos podría continuar la codificación oficial de ese derecho.

La información sobre la "European Social Week, Bruselas, septiembre 2010" y la presentación del libro Fe y justicia en el corazón de la misión, de las Jornadas sociales de la Compañía de Jesús en España (Los Negrales, mayo 2009) corrió a cargo del jesuita HIGINIO PI, Delegado del Sector social de la Provincia de España de la Compañía de Jesús. La Semana Social es la tercera que se celebra, intentando reunir a personas e instituciones de la Compañía que se mueven en el ámbito de la acción social, así como a los sectores sociales de las provincias jesuitas. El libro, que recoge las ponencias y debates del encuentro celebrado en mayo de 2009, se cierra con el documento "Rasgos de identidad y misión de las obras del sector social", preparado por la Comisión Interprovincial de Apostolado Social de España. Anunció también Higinio Pi que el próximo encuentro de EUROJESS se celebrará del 24 al 27 de agosto de 2011 en Ginebra con el tema "Gobernanza global en crisis": se trabajará en relación con las instituciones internacionales que tienen su sede en esa ciudad suiza.

Sobre el nuevo proyecto de Universidad Loyola Andalucía, que ha nacido en la Provincia Bética, informó el jesuita ILDEFONSO CAMACHO, que es el Presidente del Patronato de la Fundación Universidad Loyola Andalucía. Expuso el origen del proyecto, su vocación inequívocamente ignaciana y jesuita, subrayando la voluntad del P. General de contar en él con una decidida implicación de laicos. La Memoria del proyecto fue ya presentada oficialmente en la Junta de Andalucía y se está a la espera de la Ley de Reconocimiento del Parlamento Andaluz. En el origen de este proyecto está ETEA (Facultad de Ciencias Económicas y Empresariales) de Córdoba, pero la nueva universidad tendrá campus también en Sevilla. Se cuenta para el proyecto con la colaboración de la empresa ABENGOA.

Patxi Álvarez de los Mozos intervino a continuación como nuevo Director del Secretariado S.I. para la Justicia Social en Roma, cargo que ocupará desde comienzos 
del año 2011 , sustituyendo al anterior, Fernando Fernández Franco, quien asistente habitual a las reuniones del Grupo, había excusado su asistencia. Informó en primer lugar de la decisión del P. General de la Compañía de incorporar explícitamente a este secretariado las tareas relativas al medio ambiente (por eso pasará a llamarse Secretariado para la Justicia Social y la Ecología). Se detuvo luego en explicar el trabajo que se va haciendo desde el Secretariado en la coordinación de tareas de incidencia: se han formado así cinco redes de incidencia ignaciana (migraciones, pazy derechos humanos, ecología, educación, gobernanza de recursos naturales), que son coordinadas desde distintas provincias jesuitas de todo el mundo.

JoSÉ M. MARGENAT, propuso como actividad del Grupo la creación y mantenimiento de un foro permanente del Grupo Fomento Social en www.revistadefomentosocial así como de unas páginas ordinarias en la edición en papel de la Revista de Fomento Social.

\section{Asamblea estatutaria del Grupo}

Como en años anteriores, el encuentro concluyó con la asamblea estatutaria, que esta vez tenía que elegir nuevo Secretario para proponerlo al P. Provincial de España. Lo hizo en votación secreta, resultando elegido por una amplia mayoría el actual secretario José María Margenat.

Se discutieron a continuación otros aspectos del funcionamiento y misión del grupo como un ámbito de reflexión del sector social de la Compañía de Jesús en España.

Por último se procedió a elegir el tema para el encuentro del próximo año (que se celebrará los día 25 y 26 de noviembre). Se sugirieron una serie de temas, resultando elegido el de "Justicia y ecología", con el deseo de que se preste en él una especial atención a la relación con el desarrollo y a las orientaciones particulares de la Compañía sobre este tema. 